\title{
$\mathbb{B} \Delta+$ COMMUNICATIONS MATERIALS
}

ARTICLE

Check for updates https://doi.org/10.1038/s43246-020-00106-x OPEN

\section{Stretchable micro-scale concentrator photovoltaic module with $15.4 \%$ efficiency for three-dimensional curved surfaces}

\author{
Daisuke Sato (1) ${ }^{1 凶}$, Taizo Masuda ${ }^{2,3}$, Kenji Araki ${ }^{4,5}$, Masafumi Yamaguchi ${ }^{4}$, Kenichi Okumura ${ }^{2}$, Akinori Sato ${ }^{2}$, \\ Ryota Tomizawa ${ }^{2}$ \& Noboru Yamada (i) ${ }^{6}$
}

Stretchable photovoltaics are emerging power sources for collapsible electronics, biomedical devices, and buildings and vehicles with curved surfaces. Development of stretchable photovoltaics are crucial to achieve rapid growth of the future photovoltaic market. However, owing to their rigidity, existing thin-film solar cells based predominantly on silicon, compound semiconductors, and perovskites are difficult to apply to 3D curved surfaces, which are potential real-world candidates. Herein, we present a stretchable micro-scale concentrator photovoltaic module with a geometrical concentration ratio of $3.5 \times$. When perfectly fitted on a 3D curved surface with a sharp curvature, the prototype module achieves an outdoor power conversion efficiency of $15.4 \%$ and the daily generated electricity yield improves to a maximum of $190 \%$ relative to a non-concentration stretchable photovoltaic module. Thus, this module design enables high areal coverage on 3D curved surfaces, while generating a higher electricity yield in a limited installation area.

\footnotetext{
${ }^{1}$ Department of System Safety, Nagaoka University of Technology, 1603-1 Kamitomioka, Nagaoka, Niigata 940-2188, Japan. ${ }^{2}$ S-Frontier division, Toyota Motor Corporation, 1200 Mishuku, Susono, Shizuoka 410-1193, Japan. ${ }^{3}$ Institute for Advanced Science, The University of Electro-Communications, 1-5-1 Chofugaoka, Chofu, Tokyo 182-8585, Japan. ${ }^{4}$ Research Center for Smart Energy Technologies, Toyota Technological Institute, 2-12-1 Hisakata, Tempaku, Nagoya, Aichi 468-8511, Japan. ${ }^{5}$ Faculty of Engineering, Research Center for Sustainable Energy \& Environmental Engineering, University of Miyazaki, 1-1 Gakuen Kibanadai-nishi, Miyazaki, Miyazaki 889-2192, Japan. ${ }^{6}$ Department of Mechanical Engineering, Nagaoka University of Technology, 1603-1 Kamitomioka, Nagaoka, Niigata 940-2188, Japan. ${ }^{凶}$ email: sato_daisuke@vos.nagaokaut.ac.jp
} 
A ccording to a recently reported scenario regarding the growth of the photovoltaic (PV) market, it is projected that the global cumulative installed PV capacity will be 40 TW by $2040^{1}$, even though it is presently below $1 \mathrm{TW}^{2}$. The highest recorded power conversion efficiency of crystalline silicon (Si) solar cells, which have been the most predominant PV technology for decades, is $26.7 \%^{3}$, and this record efficiency is very close to the theoretical efficiency limit, which is $29.4 \%{ }^{4}$. Si modules, which accounted for $\sim 90 \%$ of all commercially available PV modules produced in $2013^{5}$, have been primarily installed on flat roofs of residential buildings and on vast expanses of land, often referred to as mega-solar power plants. To realize the aforementioned 2040 scenario, further diversification of PV applications-specifically, overcoming the limitations of the installation features-is becoming increasingly important. One of the most advantageous installation features of PV modules is coverage on curved surfaces, and PV modules that incorporate flexible and thin-film solar cells, including thin-film $\mathrm{Si}^{6}$, $\mathrm{CIGS}^{7}$, $\mathrm{CdTe}^{8}$, perovskite ${ }^{9,10}$, and III-V compounds ${ }^{11,12}$, could be suitable candidates. These modules can easily cover $2 \mathrm{D}$ curved surfaces (e.g., toroidal surfaces) ${ }^{13-15}$; however, their ability to fit perfectly on 3D curved surfaces (e.g., spherical surfaces), especially those with sharp curvature, is limited because they are inherently brittle and non-stretchable ${ }^{16}$. The surfaces of walls/ roofs, wearable devices, artificial satellites, and small mobiles, including automobiles and flying vehicles, which are promising applications for PV modules, have 3D curved surfaces with sharp curvatures owing to considerations related to appearance and/or aerodynamics. Thus, the availability of PV modules that can fit perfectly on such 3D curved surfaces and require a relatively small installation area to generate higher electricity yields, as independent power sources, are highly desired.

The development of stretchable electronics ${ }^{17}$ is crucial as this technology is required for the manufacture of PV modules that can completely cover the arbitrary 3D curved surfaces that are characterized by sharp curvatures. Rapid and significant progress has been made in the development of stretchable circuits ${ }^{18,19}$ and in the mounting processes of micro/nano-scaled semiconductor devices on stretchable materials ${ }^{20,21}$; this has stimulated considerable research interest in flexible displays ${ }^{22}$, curvilinear digital cameras $^{23}$, bio-integrated systems ${ }^{24,25}$, and other such applications. As an example of a PV-related technology, stretchable organic solar cells ${ }^{26-29}$ have garnered significant attention because they show great potential for large-area manufacturing. However, compared with semiconductor-based inorganic solar cells, such as Si and III-V compounds, they are associated with several drawbacks, including lower power conversion efficiencies (at most $\sim 10 \%$ ) and inferior durability. Another example of a PVrelated technology is the integration of micro/nano-scaled inorganic solar cells onto soft and stretchable substrates ${ }^{30-32}$. Although inorganic solar cells show higher power conversion efficiencies, they are inherently rigid and brittle. Hence, to ensure stretchability, they need to be arranged such that gaps are left between adjacent solar cells, providing an elastic area and/or space for electrical wiring. However, leaving such gaps deteriorates electricity yield per module area. Previous studies have primarily highlighted high stretchability in the axial direction, stating that even in the stretched state, solar cells did not show any decrease in conversion efficiency (not generated power per module area). However, the power-generation performance per module area when they are attached to actual 3D curved surfaces has not yet been investigated in detail. Additionally, a trade-off relationship between power generation per module area and stretchability is associated with this technology, because an increase in the gaps between the solar cells, i.e., a decrease in the area occupied by the solar cells, enhances stretchability.
Concentrator photovoltaics (CPV) could be a solution to this drawback. In CPVs, inexpensive concentrator optics collect sunlight into small-area solar cells so that high power generation can be obtained with relatively low solar-cell usage ${ }^{33}$. In this architecture, the solar-cell area is necessarily smaller than the module aperture area because the solar cells are arranged with some gaps between them. If the module components (e.g. concentrator, cell mounting substrate, etc.) are made from stretchable materials, more of the sunlight incident on the module aperture can be collected via concentration, while ensuring high areal coverage on 3D curved surfaces. Originally, CPV systems were developed for large-scale power plants ${ }^{34}$, in which highconcentration CPV modules with geometrical concentration ratios $C_{\mathrm{g}}$ ranging from several hundreds to one thousand ${ }^{35-37}$ were mounted on big-bonded sun-tracking systems. Subsequently, some of the authors proposed low-concentration static CPV $\left(C_{\mathrm{g}} \leq 4 \times\right)$, and clarified that optimally designed concentrators have wide acceptance operation angles of several tens of degrees without sun-tracking ${ }^{38,39}$.

In this study, a stretchable micro-scale CPV module with $C_{\mathrm{g}}=$ $3.5 \times$ for static (non-sun-tracking) operation is designed and developed. The designed module $(32 \mathrm{~mm} \times 40 \mathrm{~mm})$ consists of stretchable materials, including a silicone concentrator lens and a thermoplastic polyurethane sheet, and a rigid III-V triplejunction solar cell. When perfectly fitted on a 3D curved surface with a sharp curvature, a prototype module achieves an outdoor power conversion efficiency of $15.4 \%$ and the daily generated electricity yield improves to a maximum of $190 \%$ relative to a non-concentration stretchable PV module.

\section{Results}

Module design and prototyping. Photographs and a schematic top side view of the stretchable micro-scale CPV module are shown in Fig. 1. In addition to being flexible (Fig. 1a), the prototype module was also stretchable (Fig. 1b). Thus, it could fit perfectly on a 3D curved surface, such as a spherical surface with a curvature radius, $R=100 \mathrm{~mm}$, without wrinkling, as shown in Fig. 1c. The curvature radius, $R$ of the sharpest curve in the roof of most passenger vehicles is $\sim 1000 \mathrm{~mm}$, and the stretchability of the prototype module permitted it to fully cover car roofs without gaps, enabling high areal coverage. It is worth noting that a smaller curvature radius implies a sharper curved surface. Additionally, the prototype module could be fitted on a motorcycle helmet (see Supplementary Fig. 1a), which has a nonspherical 3D curved surface (this could be one of its possible applications, i.e., supplying energy to the interior cooling systems of helmets ${ }^{40}$ ); moreover, the module could fit perfectly on an airfoil-shaped surface (see Supplementary Fig. 1b), which has sharper and more complex curves, with curvatures that vary by position; it could also fit perfectly on a concave surface (see Supplementary Fig. 1c). As shown in Fig. 1d, with the exception of the solar cells that were rigid (i.e., the GaInP/GaInAs/Ge triplejunction cells), the prototype module consisted of stretchable materials, namely, the thermoplastic polyurethane (TPU) sheet with the screen-printed electrode pattern and the silicone lens array. The triple-junction cells were encapsulated by the stretchable silicone lens, and the structure of the modules was basically the same as those of light-emitting diode (LED) packages, to which large-scale mounting technologies can be applied $^{41}$. The lens-encapsulating design is advantageous because it reduces the number of lens-air interfaces penetrated by sunlight, implying a lower Fresnel reflection loss at the interfaces between dissimilar materials.

In applications that require the covering of curved surfaces, the module should be as thin and as light weight as possible. This is 


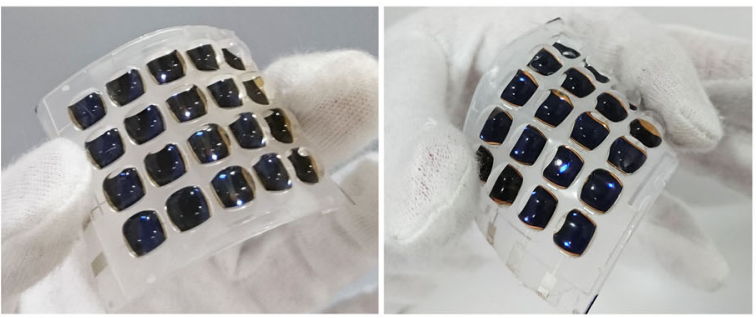

d
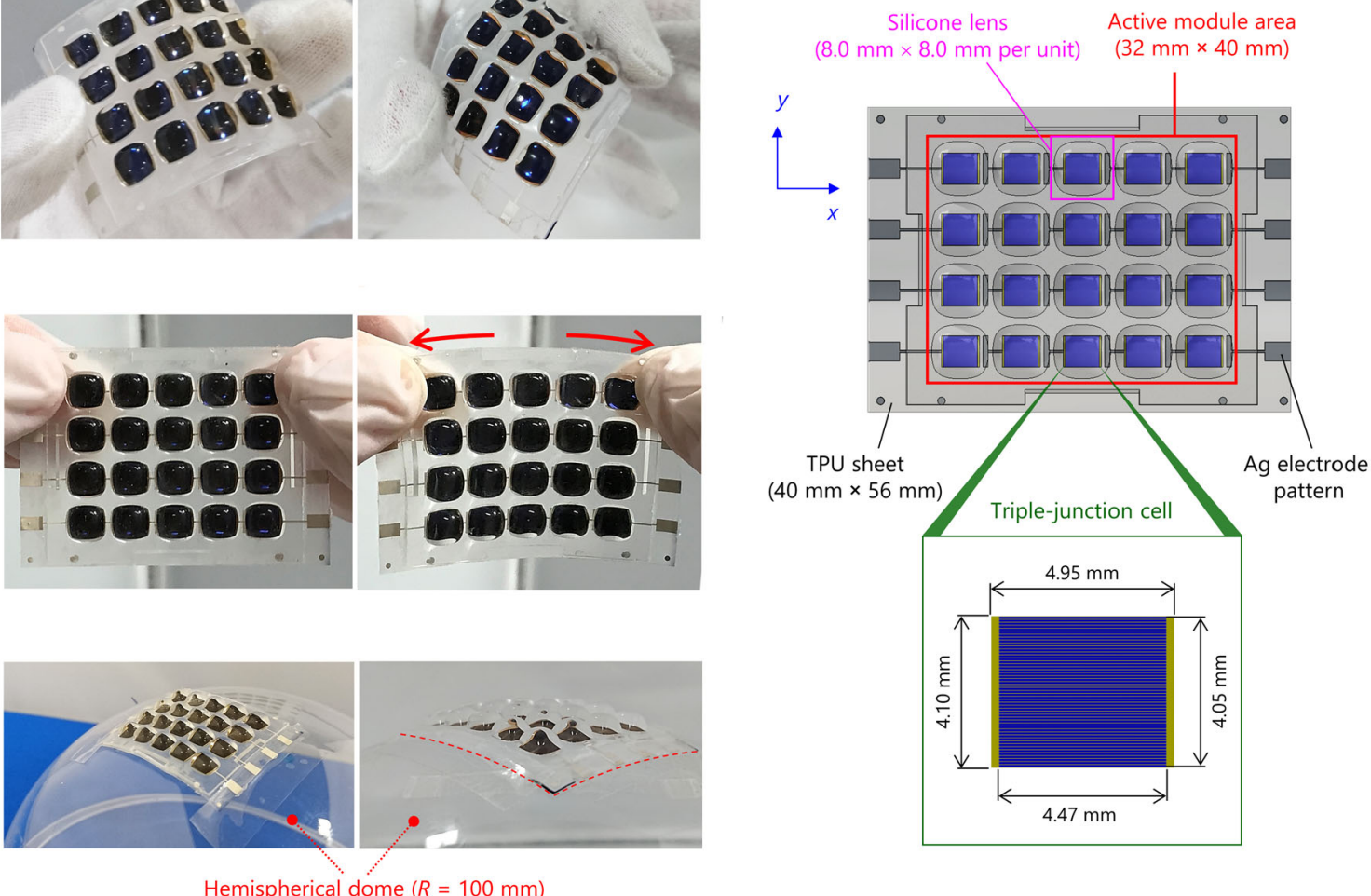

Hemispherical dome $(R=100 \mathrm{~mm})$

Fig. 1 Stretchable micro-scale CPV module. a-c Photographs of prototype module. a Flexibility, (b) Stretchability (left: relaxed state; right: stretch state), and (c) Module covering a hemispherical dome with curvature radius, $R=100 \mathrm{~mm}$. $\mathbf{d}$ Schematic representation of the top side view of prototype module.

particularly crucial with respect to appearance, the ease with which it is carried (i.e., for wearable devices), and the improvement of the power consumption ratio (for small mobiles). Therefore, a micro-scale CPV design, which is a state-of-the-art $\mathrm{CPV}$ technology, involving the use of miniaturized lenses (in the order of $\sim 1-10 \mathrm{~mm}$ ) and solar cells (in the order of $\sim 0.1-1 \mathrm{~mm}$ ) were employed. Miniaturizing the concentrator and the solar cell offers the advantages of less absorption loss owing to the thinner concentrator, better heat dissipation from the solar cells, and a thinner module thickness, i.e., a lighter module weight, owing to the shorter focal length ${ }^{42,43}$. The thickness and weight per unit area of the prototype module were $4.1 \mathrm{~mm}$ (silicone lens, $4.0 \mathrm{~mm}$; TPU sheet, $0.1 \mathrm{~mm}$ ) and $2.84 \mathrm{~kg} \mathrm{~m}^{-2}$ (almost the same as that of a $1.2-\mathrm{mm}$ thick glass substrate), respectively. The geometrical concentration ratio was determined as, $C_{\mathrm{g}}=A_{\text {lens }} / A_{\text {cell }}=3.5 \times$, where $A_{\text {lens }}$ represents the unit lens aperture area $(8.0 \mathrm{~mm} \times 8.0$ $\mathrm{mm})$ and $A_{\text {cell }}$ represents the active power-generation area of the triple-junction cell $(4.05 \mathrm{~mm} \times 4.47 \mathrm{~mm})$. The triple-junction cells with a total area of $4.10 \mathrm{~mm} \times 4.95 \mathrm{~mm}$, including the electrode area were arranged with 3.05 and $3.90 \mathrm{~mm}$ gaps between them in the $x$ and $y$ directions, respectively, forming a $4 \times 5$ array. The ratio of the total cell area to the active powergeneration area of the module $(32 \mathrm{~mm} \times 40 \mathrm{~mm})$ was $31.7 \%$, and the ratio of the active cell area to the active module area was 28.3\%. Several micro-scale CPV modules employing submillimeter-scale solar cells have been recently reported $44-48$. Such miniaturized solar cells can also be applied to the present module design. To ensure equivalent power-generation performance and its incidence-angle dependency to those of the present design, the solar cells need to be downscaled while maintaining $C_{\mathrm{g}}$ and the similarity of the optical system. In that case, because the unit-lens side length, lens thickness, and interval between the active lens islands decrease in proportion to the downscaling degree, the rigid active lens islands are subdivided, which would improve the flexibility of the module. As the silicone lens is soft and flexible, it is supposed not to impede the module flexibility as much as the solar cell. It is important to note that although the concentrator lens itself is scalable, power-generation performance and its incidence-angle dependency can vary with changes in the ratio of the lens aperture area to the solar-cell area (i.e., $C_{\mathrm{g}}$ ).

The non-axisymmetric aspheric lens designed in our previous study $^{39}$ was used in this module. The concentrator lens was designed taking into consideration the incidence-angle characteristics of the annual solar irradiance on a car roof. In the lens design, the optimal lens-geometry parameters that maximized the annual irradiance concentrated on the triple-junction cell were determined via optical analysis using ray-tracing simulation. In the present lens design, the active area loss-that is, the 1-mmthick flat area formed between the active lens islands that does not contribute to sunlight concentration on the solar celloccupied $28.9 \%$ in the active module area (i.e., $32 \mathrm{~mm} \times 40 \mathrm{~mm}$ shown in Fig. 1d). This proportion depends on the lens design method and $C_{\mathrm{g}}$. Although in the lens design method used in this study, the smaller $C_{\mathrm{g}}$ can decrease the proportion of the active area loss (eventually becoming zero for $C_{\mathrm{g}}=1.5 \times$ ), the flexibility of the module would be degraded.

The module prototyping process was as follows: (1) a stretchable conductive paste was screen-printed on the TPU sheet, forming the electrode pattern; (2) the triple-junction cells were mounted on the electrode pattern via die-bonding and wirebonding; (3) the silicone lens was formed on the cell-mounted TPU sheet via injection molding.

Stretch dependency of power-generation performance. Photographs of the prototype module under relax and asymmetrical 
a

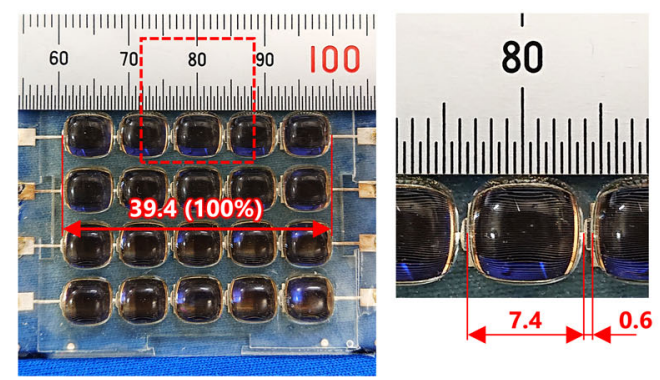

C

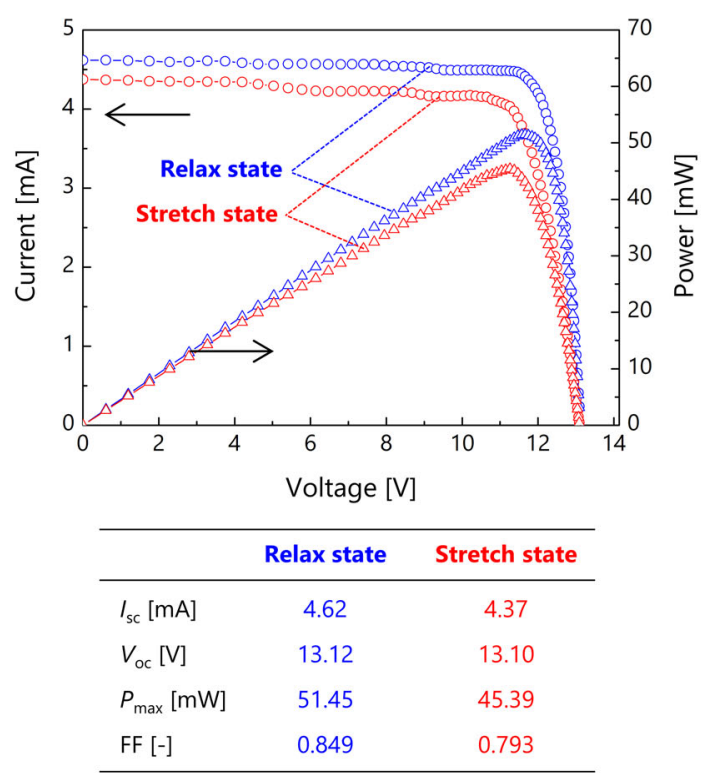

b

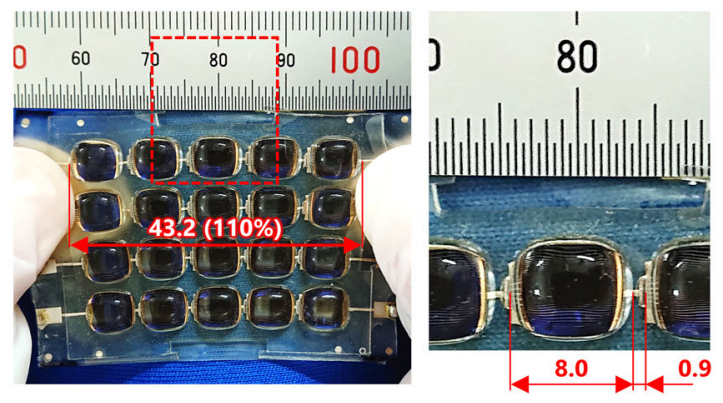

d

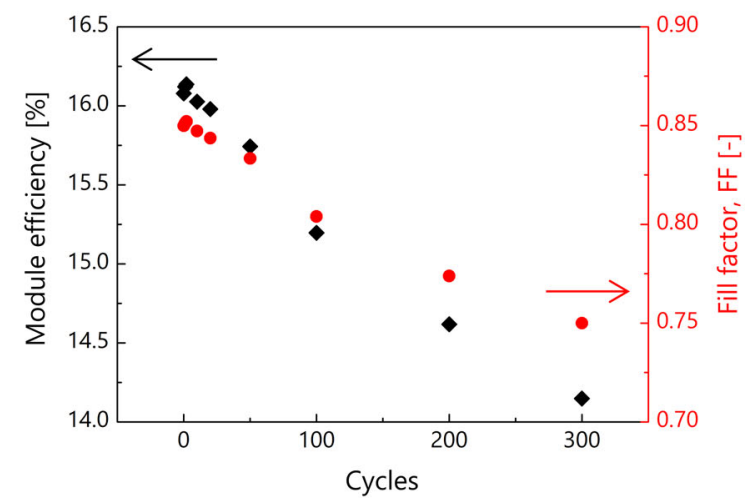

Fig. 2 Power-generation characteristics under stretch state. Photographs of the prototype module under (a) relax and (b) maximum stretch (10\% strain) states (Unit: $\mathrm{mm}$ ). The right-side photographs are magnifications of the region marked by red-colored rectangle in the left-side photographs. c Current-voltage $(I-V)$ and power-voltage $(P-V)$ characteristics under relax and maximum stretch states. $I_{\mathrm{sc}}, V_{\mathrm{oc}}, P_{\text {max }}$ and $\mathrm{FF}$ are short-circuit current, open-circuit voltage, generated power, and fill factor, respectively. d Cycling test showing the module conversion efficiency and FF when stretched by $10 \%$ up to 300 cycles. The $I-V$ and $P-V$ characteristics were measured for uppermost string in (a) and (b) at indoor 1 sun (1000 W m $\left.\mathrm{m}^{-2}\right)$ irradiation and room temperature $\left(25^{\circ} \mathrm{C}\right)$. The module conversion efficiency was calculated as the ratio of $P_{\max }$ per active module area (one string: $8 \mathrm{~mm} \times 8 \mathrm{~mm} \times 5$ lenses) to irradiance $\left(1000 \mathrm{~W} \mathrm{~m}^{-2}\right)$.

stretching states are shown in Fig. 2a, b, respectively. The maximum strain of the uppermost string consisting of five seriesconnected triple-junction cells was $10 \%(39.4 \mathrm{~mm} \rightarrow 43.2 \mathrm{~mm})$. In the maximum stretch state, strains in the thinner part (i.e., the trench formed between the active lens islands) and in the thicker part (i.e. the active lens island) were $50 \%(0.6 \mathrm{~mm} \rightarrow 0.9 \mathrm{~mm})$ and $8.1 \%(7.4 \mathrm{~mm} \rightarrow 8.0 \mathrm{~mm})$, which was smaller than that of the thinner part, respectively. This relationship is consistent with the deformation mechanism of stretchable PVs reported in previous studies $^{30,31}$. The maximum strain of $10 \%$ is smaller than that of the record value $\left(95 \%{ }^{32}\right)$. This is because the overall module stretchability is restricted by the solar cells, in which the stress concentration occurs near the vertices of the rigid solar cells, while the stress occurring at the interface between silicone lens and TPU sheet is much smaller than the maximum stress (see left-hand color contour in Supplementary Fig. 2b). The stress concentration at the vertices of the solar cells can be expected to be mitigated by employing the structured stretchable substrate instead of the flat TPU sheet, based on the outcome of prior studies $^{30,31}$. As another approach, rounding the solar-cell vertices (i.e., employing circular solar cells) can contribute to a significant reduction in the maximum stress (see Supplementary Fig. 3). The current-voltage $(I-V)$ and power-voltage $(P-V)$ characteristics under relax (i.e., non-deformation) and maximum stretch (i.e., $10 \%$ strain) states are shown in Fig. 2 c. Under the stretch state, the generated power $P_{\max }$ was $12 \%$ smaller than that under the relax state. The reasons for the performance degradation were as follows: (1) the lens deformation deteriorated the concentration performance (i.e., optical efficiency), resulting in a $5 \%$ decrease in the short-circuit current $\left(I_{\mathrm{sc}}\right)$; $(2)$ the ohmic resistance of the electrode pattern printed on the TPU sheet increased, which was shown as reduction in the fill factor (FF). Thinning the flat part formed between the active lens islands can suppress the deformation of the active lens island (i.e., deterioration of the concentration performance) while retaining the overall module stretchability (see Supplementary Fig. 2c, d). As shown in Fig. 2d, when a stretch cycle was applied, the $P_{\text {max }}$ and module conversion efficiency degraded owing to increases in the ohmic resistance of the printed electrode pattern with increases in the cycle number. Given the above stretch dependency of the power-generation performance, it can be said that the present module design is unsuitable for wearable applications. Conversely, as demonstrated 
a
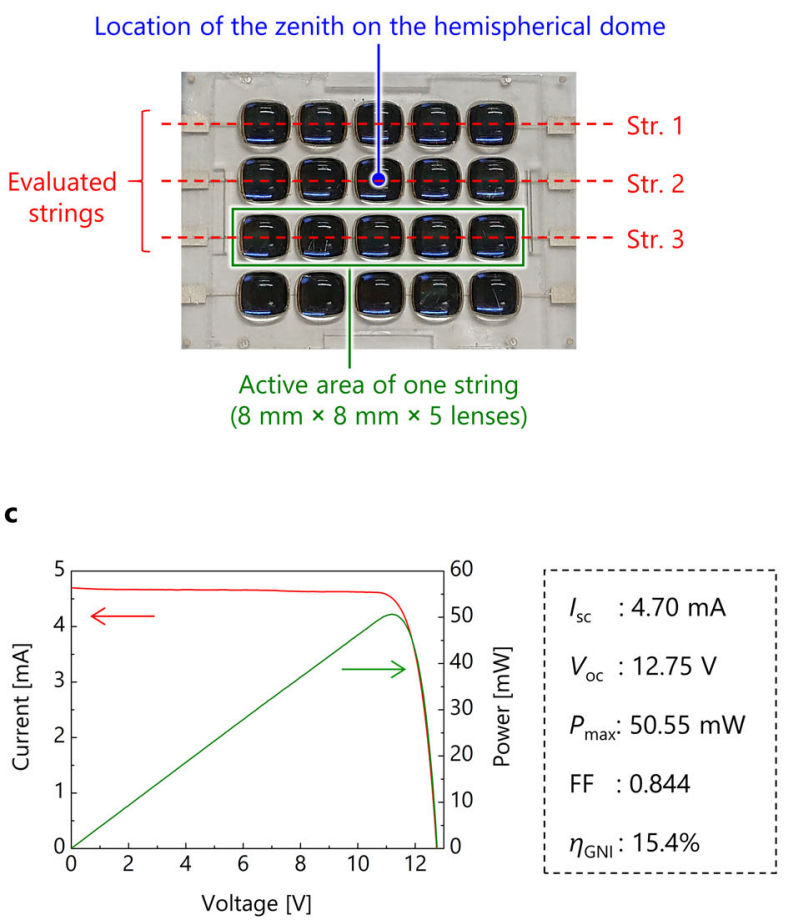

b

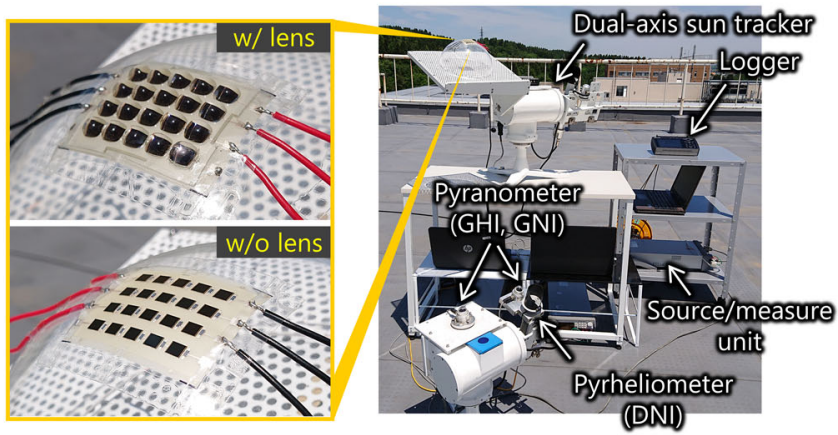

d

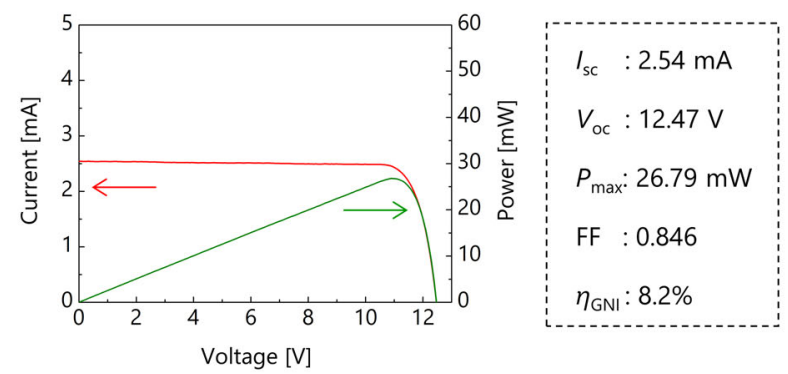

Fig. 3 Outdoor investigation of fundamental I-V characteristics. a The three evaluated strings and the cell-lens positioned at the zenith on the hemispherical dome during the outdoor tests. b Photograph of the experimental setup for the outdoor instantaneous measurement of $I-V$ characteristics. c, $\mathbf{d} I-V$ curves of string 2 (center string) under a clear-sky condition, w/ and w/o lens, respectively (global normal irradiance: $\mathrm{GNI}=1025 \pm 1 \mathrm{~W} \mathrm{~m}^{-2}$, direct normal irradiance: $\left.\mathrm{DNI}=868 \pm 1 \mathrm{~W} \mathrm{~m}^{-2}\right) . I_{\mathrm{sc}}, V_{\mathrm{oc}}, P_{\max }, \mathrm{FF}$, and $\eta_{\mathrm{GNI}}$ are short-circuit current, open-circuit voltage, generated power, fill factor, and $\mathrm{GNI}-$ based module conversion efficiency, respectively. $\eta_{\mathrm{GNI}}$ was calculated as the ratio of $P_{\max }$ per active module area (one string: $8 \mathrm{~mm} \times 8 \mathrm{~mm} \times 5$ lenses) to GNI. (w/ lens, with lens; w/o lens, without lens).

below by the outdoor power-generation performance, the present $\mathrm{CPV}$ is advantageous in the fixed installation on a $3 \mathrm{D}$ curved surface with sharp curvature over the existing technologies.

Outdoor power-generation performance on a $3 \mathrm{D}$ curved surface. To evaluate the power-generation performance when attached to a $3 \mathrm{D}$ curved surface, the prototype module was attached to a hemispherical dome with a curvature radius, $R=$ $100 \mathrm{~mm}$. Thereafter, outdoor tests were performed at Nagaoka University of Technology (Nagaoka city, Japan; latitude, $37.42^{\circ}$; longitude, $\left.138.78^{\circ}\right)$. During the outdoor tests, the powergeneration performance of the three strings, each consisting of five series-connected triple-junction cells as shown in Fig. 3a, were measured, and the cell-lens pair located at the center of the measured $3 \times 5$ array was positioned at the zenith of the hemispherical dome.

As a fundamental power-generation performance indicator, $I-V$ characteristics were first measured under the condition that the zenith of the hemispherical dome on which the prototype module was attached was facing the sun (i.e., the differences among the incidence angles of the unit lenses were minimum). Figure $3 \mathrm{~b}$ shows the setup used during the outdoor tests. The $I-V$ characteristics of each string were independently and simultaneously measured using two-channel source measurement units. During the experiments, global horizontal irradiance (GHI) and global normal irradiance (GNI) were measured using pyranometers, while direct normal irradiance (DNI) was measured using a pyrheliometer. Both devices were mounted on another sun tracker installed close to the prototype modules. To quantitatively confirm the improvement of power-generation performance as a function of concentration, the $I-V$ characteristics of the stretchable PV module without lens were also measured. Figure $3 \mathrm{c}$, d shows the $I-V$ curves of string 2 (center string) under a clear-sky condition with and without lens, respectively. When the prototype module was fitted on the spherical surface, the outline of the active module area shown in Fig. 1d (i.e., $32 \mathrm{~mm} \times 40 \mathrm{~mm}$ ) was elongated by $\sim 1 \mathrm{~mm}$ in directions both parallel and orthogonal to the string directions, which corresponds to $\sim 3 \%$ strain and is smaller than $1 / 3$ of the maximum value (10\%). Consequently, although the ohmic resistance of the printed electrode pattern on the TPU sheet somewhat increased, that had a minor effect on the $I-V$ characteristics even under the possible best irradiance (i.e., highest current output) condition. The FF of the CPV module (w/ lens) was slightly lower than that of the non-concentration module (w/o lens) owing to the degradation of irradiance uniformity in the cell area caused by non-uniform concentration $^{49}$. On the other hand, enhancing the short-circuit current $\left(I_{\mathrm{sc}}\right)$ and the open-circuit voltage $\left(V_{\mathrm{oc}}\right)$ contributed to an increase in the generated power, $P_{\max }$ up to 1.88 times; consequently, a GNI-based module conversion efficiency, $\eta_{\mathrm{GNI}}$, of $15.4 \%$ was realized, and it is worth noting that $\eta_{\mathrm{GNI}}$ is defined as the ratio of $P_{\max }$ per active module area to GNI. Additionally, the $I-V$ characteristics of strings 1 and 3 were basically the same as those of string 2, even though the incidence angles for the unit lenses in the string were a little larger (see Supplementary Fig. 4).

In the case of the static CPV module (non-sun-tracking), the incidence angle varied with time. Furthermore, the incidence angles for the unit lenses were different when the module was attached to $3 \mathrm{D}$ curved surfaces. To clarify the daily powergeneration performance potential of the prototype CPV module, prototype modules (w/ lens and w/o lens) attached to the hemispherical domes $(R=100 \mathrm{~mm})$ were installed on horizontal and $30^{\circ}$-inclined surfaces (simulating attachment on different 


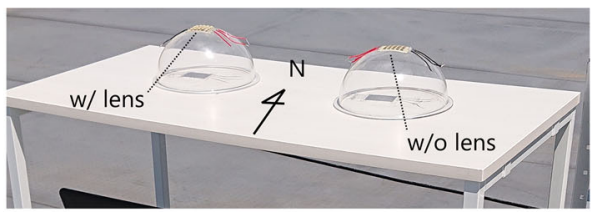

b
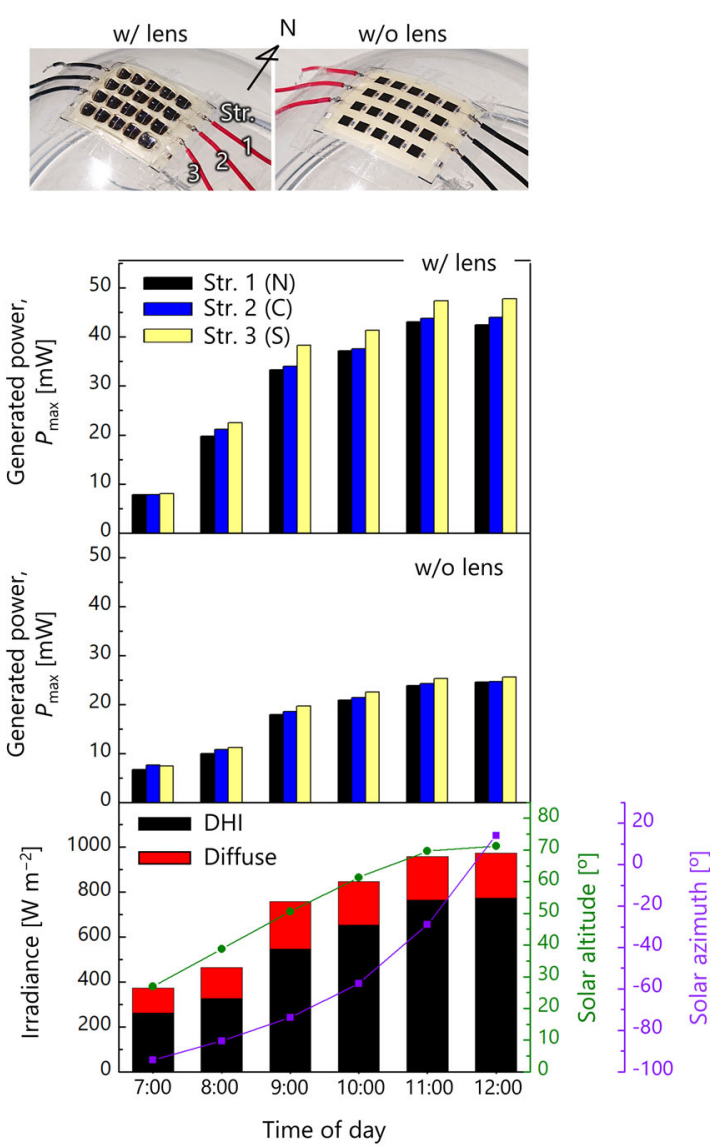

c
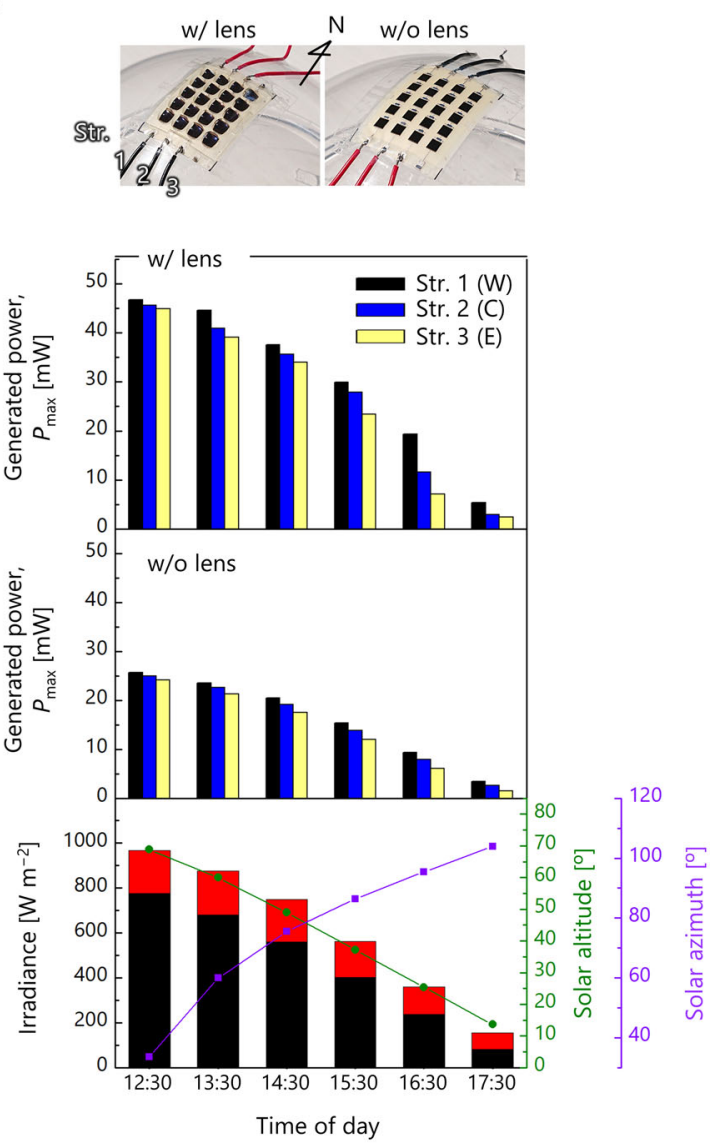

Fig. 4 Outdoor power-generation performance at representative times (prototype modules atop the hemispherical domes were installed on a horizontal surface). a Magnifications of the prototype modules in the experimental setup. b, c Measured $P_{\max }$ and irradiances (direct horizontal irradiance $(\mathrm{DHI})$, diffuse irradiance) as a function of the sun's position on May 17, 2019 (Nagaoka city, Japan). String directions were (b) east-west in AM and (c) north-south in PM. String 1 lay on the northern side in AM (black bar referred to as "N") and on the western side in PM (black bar referred to as "W"); string 2 lay on the center line of the hemispherical dome (blue bar referred to as " $\mathrm{C}^{\prime \prime}$ ); and string 3 lay on the southern side in $A M$ (yellow bar referred to as " $\mathrm{S}$ ") and on the eastern side in PM (yellow bar referred to as " $\mathrm{E}^{\prime}$ ). For the solar altitude, $90^{\circ}$ corresponded to the zenith, and for the solar azimuth, $-90^{\circ}$, $0^{\circ}$, and $90^{\circ}$ corresponded to the east, south, and west, respectively. ( $\mathrm{W} /$ lens, with lens; w/o lens, without lens).

positions on the spherical surface), and $I-V$ characteristics were continuously measured throughout the day $(\sim 7: 00-17: 30)$ on clear-sky days. Figures $4 a$, 5a show magnifications of the modules attached to the hemispherical dome in the test setups. The other setups were the same as shown in Fig. 3b. To compare the effect of string direction on power-generation performance, the string direction was changed by $90^{\circ}$ at the culmination time (approximately 12:00), i.e., the series-connected strings were oriented from east to west until 12:00, and thereafter, from north to south. String 1 lay on the northern side in AM and on the western side in PM; string 3 lay on the southern side in AM and on the eastern side in PM; and string 2 lay centrally between strings 1 and 3 . The measured generated power, $P_{\max }$, of the three strings, the horizontal irradiances, and the sun positions at different representative times are shown in Fig. $4 \mathrm{~b}, \mathrm{c}$ for the horizontally installed case, and in Fig. 5b, c for the $30^{\circ}$-inclined case (The time variation for each parameter is as shown in Supplementary Figs. 5, 6). Direct horizontal irradiance (DHI) was calculated using the measured DNI and sun's positions at the time of the day. Thereafter, the diffuse irradiance, which has a wide range of incidence angles on the horizontal surface, was defined as GHI-DHI. Given that the concentrator optics exhibited incidence-angle dependence, as shown in Supplementary Fig. 7, the generated power varied with changes in the irradiance composition (ratio of direct and diffuse irradiances), i.e., the angular irradiance distribution on the module aperture. The current output of the strings (series-connected solar cells) at each time was limited to the minimum value of the connected cells, and this depended on the incidence angle at each position on the hemispherical dome; hence, there were differences in the generated power of three strings. The enhancement of power generation by concentration (i.e., ratio of generated power of w/ 


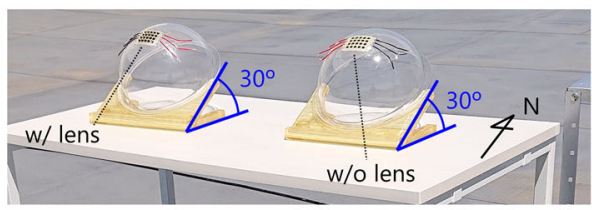

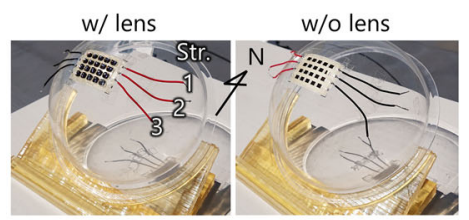

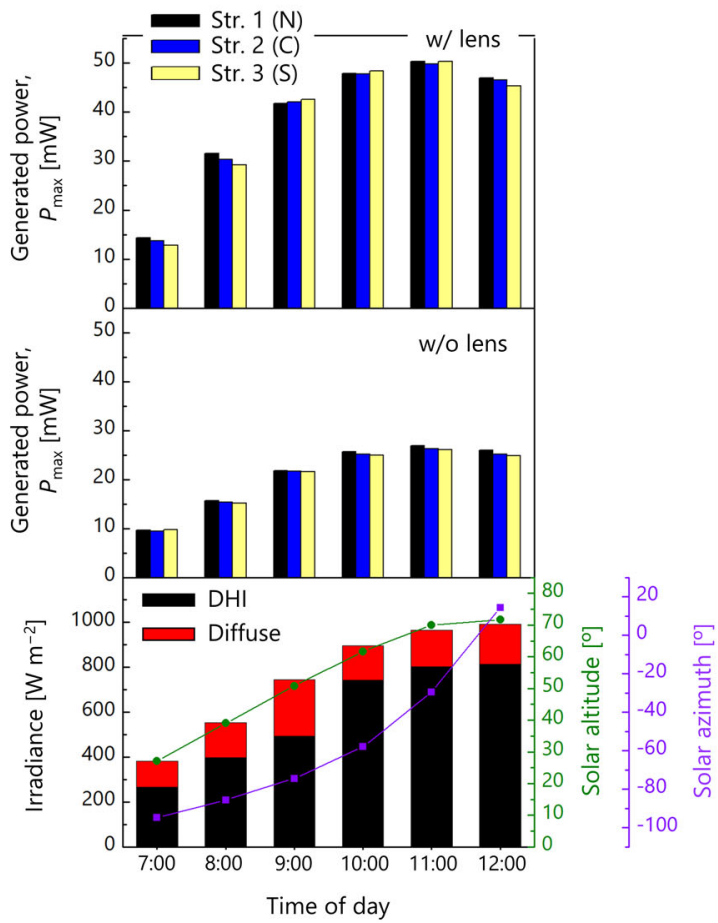

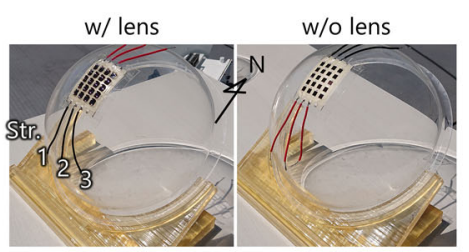

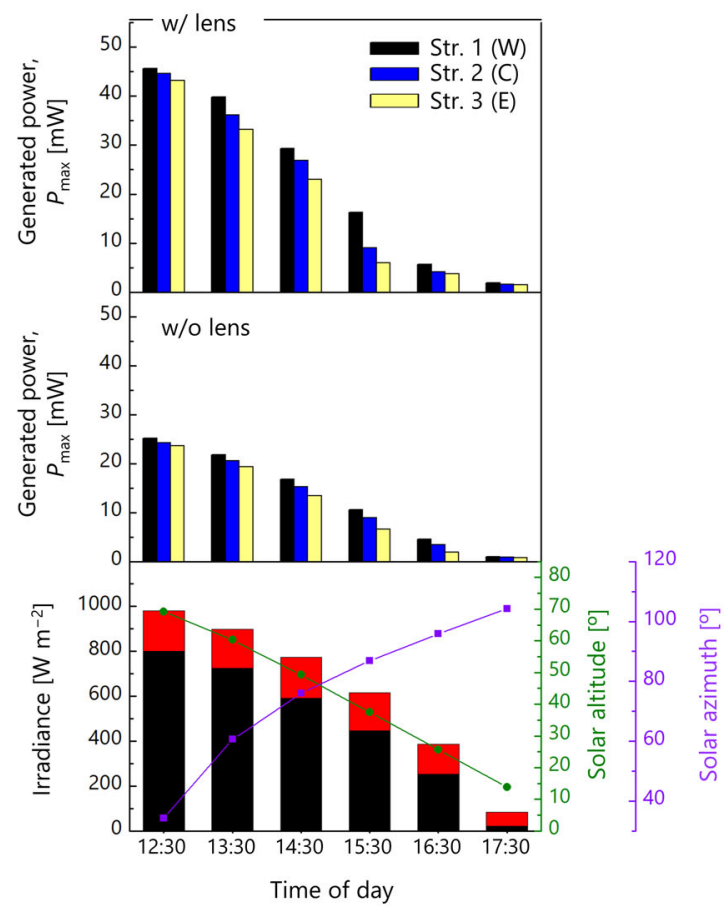

Fig. 5 Outdoor power-generation performance at representative times (prototype modules atop the hemispherical domes were installed on a $30^{\circ}$ inclined surface). a Magnifications of the prototype modules in the experimental setup. b, c Measured $P_{\text {max }}$ and irradiances (direct horizontal irradiance (DHI), diffuse irradiance) as a function of the sun's position on May 19, 2019 (Nagaoka city, Japan). The string directions were (b) east-west in AM and (c) north-south in PM. String 1 lay on the northern side in AM (black bar referred to as "N") and on the western side in PM (black bar referred to as "W"); string 2 lay on the center line of the hemispherical dome (blue bar referred to as " $\mathrm{C}^{\prime \prime}$ ); and string 3 lay on the southern side in $\mathrm{AM}$ (yellow bar referred to as "S") and on the eastern side in PM (yellow bar referred to as "E"). For the solar altitude, $90^{\circ}$ corresponded to the zenith, and for the solar azimuth, $-90^{\circ}$, $0^{\circ}$, and $90^{\circ}$ corresponded to east, south, and west, respectively. (w/ lens, with lens; w/o lens, without lens).

lens to that w/o lens) was 1.8-2.0 times during the daytime, and early in the morning or in the evening, it was significantly lower (e.g. 7:00 in Fig. 4b and 16:30 in Fig. 5c). This is because the incidence angles to some or all the lens apertures were greater than the acceptance half angles of the optics ${ }^{50}$, resulting in a reduced concentration of sunlight on the solar cells. By attaching the prototype module to the hemispherical dome (3D curved surface), the acceptance half angle of each string became smaller relative to horizontal surface installation. Nevertheless, the peak optical efficiency could be maintained provided the incidence angle to the zenith of the dome is below $50^{\circ}$ (see Supplementary Fig. 7).

\section{Discussion}

From the outdoor testing results, the accumulated generated electricity per module area (for the three strings: $8 \mathrm{~mm} \times 8 \mathrm{~mm} \times$
15 lenses) during the measurement period was calculated assuming that the three strings investigated were connected in series and in parallel, i.e., the overall current and voltage at each time was limited to the minimum value associated with the three strings. To compare the generated electricity based on the different positions on the spherical surface (i.e., between horizontal and $30^{\circ}$-inclined installations), the calculated electricity was normalized using the total GHI energy accumulated over the corresponding measurement period. Additionally, for the stretchable PV module (w/o lens), a practically impossible and ideal configuration, in which the module area was fully covered by an active solar-cell area, i.e., no interval between the solar cells, was assumed (hereafter referred to as gapless case). For the gapless case, the accumulated generated electricity was approximated as the product of that generated by the stretchable $\mathrm{PV}$ module (w/o lens) and the geometrical concentration ratio 
a
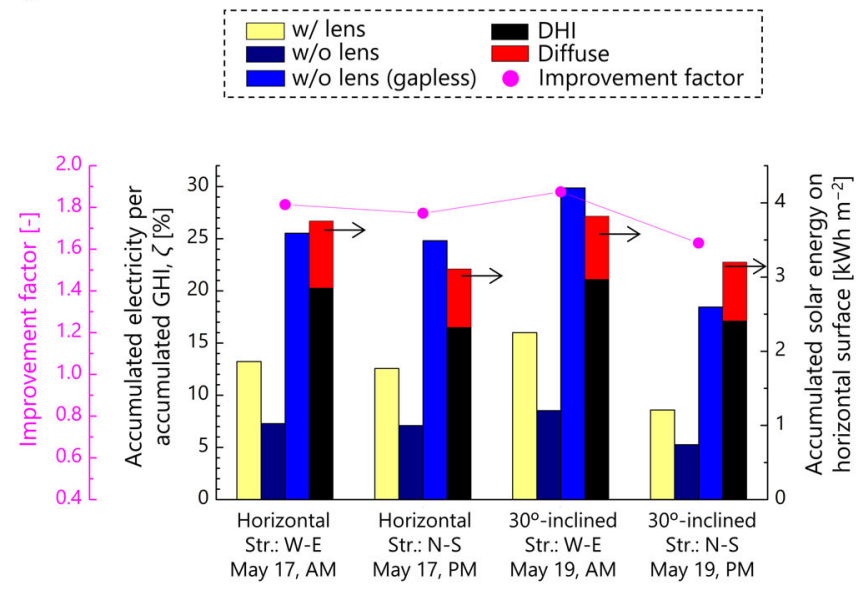

b

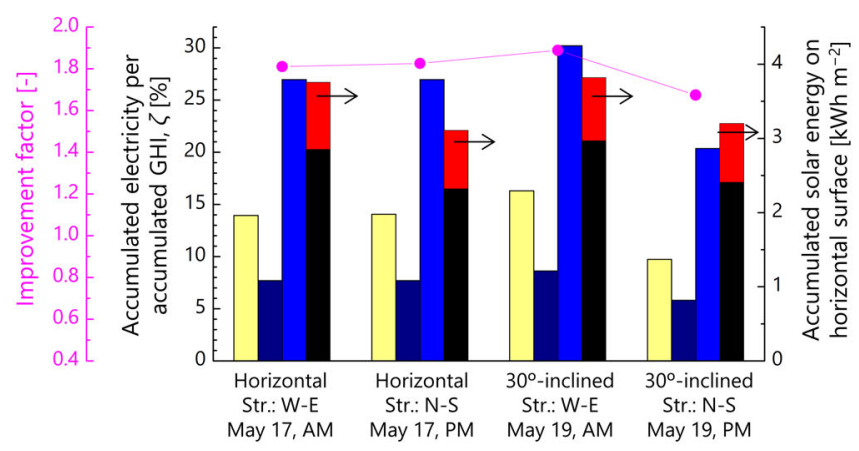

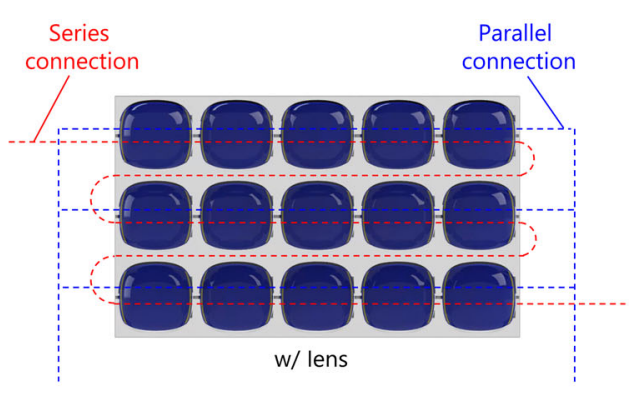
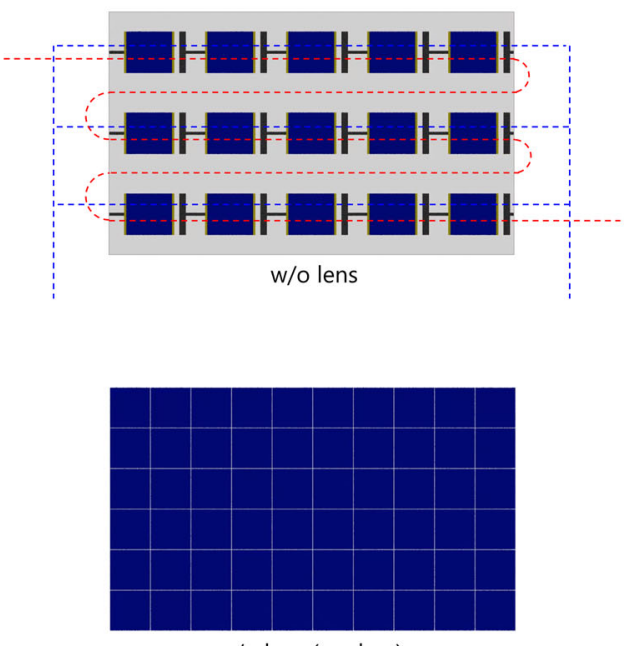

w/o lens (gapless)

Fig. 6 Accumulated electricity per module area / accumulated GHI ratio. a, b Results obtained from the three strings in the series- and parallel-connected cases, respectively. For the module without lens (w/o lens), the projected total electricity for a gapless case is also shown. The improvement factor was defined as $\zeta(\mathrm{w} /$ lens $) / \zeta(\mathrm{w} / \mathrm{o}$ lens). Global horizontal irradiance $(\mathrm{GHI})$ is sum of direct horizontal irradiance (DHI) and diffuse irradiance. c Schematic of the top view of the three module configurations (w/ lens, w/o lens, and w/o lens (gapless)) in the same module area. String connections are also shown (series connection, red; parallel connection, blue).

$\left(C_{\mathrm{g}}=3.5 \times\right)$. Figure 6 shows the accumulated electricity per module area / accumulated GHI ratio $(\zeta)$ for each of the cases shown in Figs. 4, 5. The time ranges of the integral were 7:00-12:00 and 12:30-17:30 for the string directions oriented east-west (AM) and north-south (PM), respectively. For the series- and parallel-connected cases, $\zeta$ varied in the range 8.6-16.0\% and $9.7-16.3 \%$, respectively, depending on the dome inclination angle (i.e., the position on the spherical surface) and the string direction. Basically, the current output of the solar cells was directly proportional to the received irradiance; hence, the effect of current mismatching was more significant in the seriesconnected cases. Nevertheless, comparing both connection cases, $\zeta$ practically showed the same values for the same installation modes, and it was obviously different with respect to the different installation modes (i.e., horizontal and $30^{\circ}$-inclined surface installations) for the same string directions (W-E or N-S). However, comparing the $\mathrm{w} / \mathrm{lens}$ and w/o lens cases, the improvement factor of $\zeta$, defined as $\zeta$ (w/ lens) / $\zeta$ (w/o lens), was approximately constant (1.63-1.89), i.e., the difference between the $\zeta$ of the different installation modes was mainly caused by the irradiance distribution on the spherical surface rather than the performance of the concentrator optics. It is important to note that the concentrator lens was designed so that the annual electricity yield can be maximized in the horizontal installation case (see "Lens design optimization and ray-tracing simulation" in the "Methods" section and Supplementary Fig. 8); therefore, to compare fairly the electricity yield between the installation modes, it needs to be verified throughout the year. Considering the above-mentioned sun-tracking condition, where the differences among the incidence angles to the unit lenses are minimum, the improvement factor was 1.88 , indicating that the prototype module could maintain more than $86.7 \%$ of the performance associated with the sun-tracking case, even under the unique condition that the time variation of the incidence angle to the module aperture and the differences among the incidence angles to the unit lenses were combined. Furthermore, the $\zeta$ of the prototype CPV module (w/ lens) showed a performance that was $46.6-54.0 \%$ that of the ideal gapless case, i.e., with the prototype module, the daily generated electricity yield was maintained at $\sim 50 \%$, even though the solar-cell usage had decreased by $71 \%$ relative to the gapless case, demonstrating better cost per unit of electricity yield. Furthermore, the additional advantage would be obtained by effectively utilizing the sunlight that is not concentrated on the solar cells. For example, although in this study, we used the less transparent TPU sheet because the electrode pattern can be easily formed by screen-printing, substituting highly transparent and stretchable materials (e.g., polydimethylsiloxane: PDMS) improves the module transmittance to the sunlight; consequently, unutilized sunlight for power generation can be transmitted under the module while generating the power comparable to the Si module. Therefore, also given the stretchability to be fitted to $3 \mathrm{D}$ curved surfaces with sharp 
curvature, this upgraded concept would be a promising technology for efficient dual-land use (i.e., semi-transparent $\mathrm{CPV}$ module ${ }^{51-53}$ ).

The relative importance of the module cost and the powergeneration performance are determined by considering the quantity of electricity required and the constraint of the installation area. As another design example, a CPV module with $C_{\mathrm{g}}=2.0 \times$ and the same lens aperture area as the present design $(8.0 \mathrm{~mm} \times 8.0 \mathrm{~mm}$ per unit) was considered. A ray-tracing simulation showed that the optical efficiency for normal-incident light as well as the acceptance half angle increased by $21.3 \%$ abs and $7.5^{\circ}$, respectively, compared with the present design (see Supplementary Fig. 8b). Consequently, this module, for example, can collect $73.3 \%$ of the annual irradiance on a car roof onto the solar cell (cf. $46.6 \%$ for the present design of $C_{\mathrm{g}}=3.5 \times, 100 \%$ for gapless case). Therefore, even though decreasing $C_{\mathrm{g}}$ from $3.5 \times$ to $2.0 \times$ resulted in a 1.75 -fold increase in cell usage, the annual generated electricity on a car roof increased 1.57 -fold (see Supplementary Fig. 8c).

This module concept can be applied to various curved surfaces. The sizes of the solar cells and the gaps between them can be arbitrarily selected based on the shape of the curved surfaces, i.e., the required stretchability. The optical characteristics of the concentrator lens can be tailored for an angular irradiance distribution on the targeted attachment surfaces, offering a large degree of freedom for the module design. Considering the proposed module design, basically any type of solar cell, regardless of the material from which it is made, can be applied. In this study, commercially available III-V triple-junction cells optimized for high-concentration (500-1000×) CPV (HCPV) were employed because the present design required the use of small-size solar cells. Under one-sun irradiation, the determined power conversion efficiency of the triple-junction cell was $29.8 \%$; thus, the same level of performance would be obtained even if the Si cells with the highest reported efficiency $(26.7 \%)^{3}$ were used. Additionally, given that the heat generation density of the solar cells is smaller than that of conventional HCPVs by more than two orders of magnitude, and that the aspherically shaped lens contributes to better heat dissipation owing to a larger surface area as with the fins, the temperature rise of the solar cells could be mitigated to the same level as that in conventional flat PV modules $\left(\sim 80^{\circ} \mathrm{C}\right.$ even under possibly higher temperatures, see Supplementary Fig. 9). Furthermore, with respect to weather durability, solar cells could be effectively utilized by integrating this lens-encapsulating design, and the use of thin-film solar cells would enable adaptation to more complicated curved surfaces.

In summary, in this study, a stretchable micro-scale CPV module $\left(C_{\mathrm{g}}=3.5 \times\right)$, which allows high areal coverage on $3 \mathrm{D}$ curved surfaces with sharp curvature for static (non-sun-tracking) operation, was developed and investigated. The results showed that the prototype module could fit perfectly on spherical surfaces with a curvature radius of $100 \mathrm{~mm}$, and under outdoor one-sun irradiation, the module showed a power conversion efficiency of $15.4 \%$. Additionally, relative to the non-concentration stretchable PV module, the CPV module yielded an enhancement of the total daily generated electricity by a factor of 1.63-1.89, which depended on the position of the spherical surface and the mode of electric connection (i.e., series or parallel). The solar-cell usage associated with this CPV module decreased by $71 \%$, which is indicative of a lower cost per unit of electricity generated, while the electricity yield throughout the day was $\sim 50 \%$ that of the ideal gapless case, in which the solar cells fully occupy the module aperture. Nevertheless, there is still room to improve the module efficiency and daily generated electricity to achieve cost competitiveness.

Our future studies will focus on a more detailed examination of the prototype module with respect to practical use and further optimization of the module design for enhancement of power generation and stretchability. For module-size expansion, the large-area module can be divided into submodule operational units with appropriate sizes so as to minimize the current mismatching loss resulting from irradiance distribution on the curved installation surface; thus, an optimal circuit design and control strategy are important. Additionally, given the importance of long-term reliability and lifetime issues, their consideration is also important. The effect of the periodic thermal deformation of the lens material on the mechanical stress of the encapsulated electrical components, such as bonding wires, needs to be clarified. It is also necessary to investigate the durability of the lens material against humidity, soiling, and debris. Finally, the development of coatings that do not degrade transmittance in the power-generation sensitive spectral range is an option to improve the resistance of the module to such negative factors.

\section{Methods}

Lens design optimization and ray-tracing simulation. The concentrator lens was designed considering the incidence-angle characteristics of annual solar radiation on the horizontal surface, modified by assuming a car-roof-specific environment. The reported angular irradiance model ${ }^{38}$ was used in the simulation (see Supplementary Fig. 8c, referred to as "car roof"). To obtain this angular irradiance model, the average 20-year (1990-2009) solar irradiance of 47 major Japanese cities extracted from a meteorological database (METPV-11, New Energy and Industrial Technology Development Organization (NEDO)), including both direct and diffuse sunlight on a horizontal flat surface, was modified by statistically accounting for the car-roof specific shading condition resulting from surrounding objects. For car-roof specific conditions, the following assumptions were made: the heights of the shading objects are distributed in accordance with a function in which the probability linearly decreases from $100 \%\left(\right.$ at $\left.5^{\circ}\right)$ to $0 \%\left(\right.$ at $60^{\circ}$ ); the angular irradiance is independent of the orientation angle, i.e., the car direction.

An optimum lens was defined as that which can maximize the annual solar energy reaching the solar cell, and its geometric parameters were determined via optical analysis using ray-tracing simulation and an in-house macro program with an optimization algorithm, which are both incorporated in a commercial software (LightTools 8.4.0, Synopsys, Inc., California, USA). Supplementary Fig. 8a shows the $3 \mathrm{D}$ ray-tracing simulation model. To facilitate the consideration of the crosstalk effect resulting from adjacent lenses, a $3 \times 3$ lens array was employed, and the solar cell was placed at the center of the array. The light irradiation area $(16 \mathrm{~mm} \times$ $16 \mathrm{~mm}$ ) was irradiated using AM1.5G standard spectrum rays $(300-2000 \mathrm{~nm})^{54}$ and a divergence angle of the rays emitted from the hemispherical light source was $\pm 0.265^{\circ}$ (half angle of solar disc). The angular intensity of the rays was weighted based on the above-mentioned angular irradiance distribution on a car-roof. The chromatic dispersion of the optical properties of the module components was considered, and the solar cell was assumed to be a black body (ideal absorber). The Fresnel reflection loss at the interface between dissimilar materials and the absorption loss in the lens materials were also considered. Details regarding the resultant lens geometry have been presented in the literature ${ }^{39}$.

Module prototyping. A step-by-step module prototyping process is illustrated in Supplementary Fig. 10. (Step 1) A stretchable conductive paste (XE181A, NAMICS Corp., Niigata, Japan) was screen-printed on a $0.1-\mathrm{mm}$ thick thermoplastic polyurethane (TPU) sheet (SILKLON ${ }^{\circledast}$ ES85, Okura Industrial Co., Ltd., Kagawa, Japan) to form the electrode pattern. (Step 2) Commercial GaInP/GaInAs/Ge triple-junction solar cells (High Efficiency $4 \times 4$ CPV Solar Cell, TaiCrystal International Technology Co., Ltd., Taoyuan City, Taiwan) were mounted on the printed electrode pattern via die-bonding. The solar cells were adhered to the electrode pattern via a conductive epoxy adhesive (EPO-TEK ${ }^{\circledR}$ EE129-4, Epoxy Technology, Inc., Massachusetts, USA) that was cured at room temperature $\left(23^{\circ} \mathrm{C}\right)$. Copper pieces with dimensions of $1.0 \mathrm{~mm} \times 2.0 \mathrm{~mm}$ (area) $\times 0.1 \mathrm{~mm}$ (thickness), which were coated with $\mathrm{Ni} / \mathrm{Au}$ thin films to improve the bondability with the wire, were also mounted on the printed electrode pattern by using the same process for the triple-junction cells. (Step 3) The electrode pads on the triplejunction cells and the copper pieces on the printed electrode pattern were electrically connected via wire bonding. An aluminum wire with a diameter of $25 \mu \mathrm{m}$ containing $1 \% \mathrm{Si}$ was used, and the wire bonding was performed at room temperature $\left(23^{\circ} \mathrm{C}\right)$. (Steps $\left.4-6\right)$ The silicone concentrator lens was formed on the cellmounted TPU sheet (i.e., CPV receiver) via injection molding as follows: (1) well mixed and deformed liquid-state addition-curing RTV-2 silicone resin (ELASTOSIL $^{\circledast}$ RT 601; Wacker Asahikasei Silicone Co., Ltd., Tokyo, Japan) was poured into a polymethyl methacrylate (PMMA) female mold, on which the geometry of the designed lens was carved via machining; (2) the CPV receiver was aligned into the designated position on the female mold and placed; (3) the integrated module components were cured at $20^{\circ} \mathrm{C}$ for $24 \mathrm{~h}$ in a thermostatic chamber; (4) after 
curing, the female mold was released, and finally, the formation of the CPV module shown in Fig. 1 was completed.

Outdoor experiment. Current-voltage $(I-V)$ characteristics were recorded using a two-channel source/measure unit (B2902A, Keysight Technologies, California, USA) that minimizes series resistive losses by performing four-terminal sensing. GNI, GHI were measured using pyranometers (MS-602, EKO Instruments Co., Ltd., Tokyo, Japan), while DNI was measured using a pyrheliometer (MS-54, EKO Instruments Co., Ltd., Tokyo, Japan). Both instruments were mounted on a sun tracker (STR-22, EKO Instruments Co., Ltd., Tokyo, Japan) installed close to the prototype modules. Direct horizontal irradiance (DHI) was calculated using the measured DNI and the position of the sun based on the time of day. The diffuse irradiance on the horizontal surface was then calculated using the expression: GHI-DHI.

On-tracker measurements were made under a steady clear-sky condition and two source/measure units were used to simultaneously and separately record the $I-V$ characteristics of the three strings. The measurement of the $I-V$ characteristics of the prototype CPV module was first conducted. Thereafter, the CPV module was replaced with the no-lens module, and the same measurements were performed. To prevent output voltage degradation owing to temperature rise, the test modules were shaded for one-minute after mounting on the sun-tracker, and then $I-V$ measurements were started immediately after removing the sunshade. The variations of irradiance during the series of measurements were $\pm 1 \mathrm{~W} \mathrm{~m}^{-2}$ for both GNI and DNI.

During the continuous measurements throughout the day, three source/ measure units were used to simultaneously and separately record a total of six strings for the modules with and without lenses. $I-V$ data and irradiance data were obtained at intervals of 5 and $1 \mathrm{~s}$, respectively. The total generated power of the three series-connected strings was approximated as $\min \left(I_{\mathrm{sc}_{3}}, I_{\mathrm{sc}_{2}}, I_{\mathrm{sc}_{3}}\right) \times\left(V_{\mathrm{oc}_{-1}} \times\right.$ $\left.\mathrm{FF}_{1}+V_{\mathrm{oc} \_2} \times \mathrm{FF}_{2}+V_{\mathrm{oc} \_3} \times \mathrm{FF}_{3}\right)$, while that of the three parallel-connected strings was approximated as $\min \left(V_{\mathrm{oc}_{\_} 1}, V_{\mathrm{oc} \_2}, V_{\mathrm{oc} \_3}\right) \times\left(I_{\mathrm{sc} \_1} \times \mathrm{FF}_{1}+I_{\mathrm{sc}_{-} 2} \times \mathrm{FF}_{2}+I_{\mathrm{sc}_{-} 3} \times\right.$ $\left.\mathrm{FF}_{3}\right)$. Here, $\min \left(I_{\mathrm{sc}_{1} 1}, I_{\mathrm{sc}_{2} 2}, I_{\mathrm{sc}_{3} 3}\right)$ and $\min \left(V_{\mathrm{oc}_{1} 1}, V_{\mathrm{oc}_{2} 2}, V_{\mathrm{oc}_{3} 3}\right)$ represent the minimum values of $I_{\mathrm{sc}}$ and $V_{\mathrm{oc}}$ among the three strings, respectively; and the subscripts 1,2 , and 3 represent strings 1,2 , and 3 , respectively.

Indoor experiment. The $I-V$ and $P-V$ characteristics under relax and stretch states were measured using a solar simulator (HAL-320, Asahi Spectra Co., Ltd., Tokyo, Japan) at 1-sun $\left(1000 \mathrm{~W} \mathrm{~m}^{-2}\right)$ irradiation and room temperature $\left(\sim 25^{\circ} \mathrm{C}\right)$. The irradiance was calibrated so that the $I_{\mathrm{sc}}$ under the 1-sun irradiation with AM1.5G standard spectrum can be yielded for the triple-junction cell used in the prototype module.

The dependence of optical efficiency on the incidence angle was measured under a highly collimated artificial sunlight setup constructed by one of the authors ${ }^{55}$. This artificial sunlight setup had an irradiance of 0.01 sun $\left(10 \mathrm{~W} \mathrm{~m}^{-2}\right)$ and a beam collimation angle below $0.2^{\circ}$. The prototype module attached on the hemispherical dome with a curvature radius, $R=100 \mathrm{~mm}$, was mounted on a dualaxis angle adjuster, and the optical efficiencies of the three strings were measured every $5^{\circ}$, while rotating the module around each axis in three directions (see Supplementary Fig. 7a, b). This series of measurements were repeated three times, and the optical efficiency at each incidence angle was calculated as $\eta_{\mathrm{opt}}=C_{\mathrm{f}} / C_{\mathrm{g}}=$ $I_{\mathrm{sc}}$ (w/lens) $/ I_{\mathrm{sc}}$ (w/o lens) $/ C_{\mathrm{g}}$, using the measured $I_{\mathrm{sc}}$ values obtained with the lens (i.e., under concentration) and without the lens (i.e., under no concentration). Here, $C_{\mathrm{f}}[-]$ represents the flux concentration ratio, i.e., current gain, while $C_{\mathrm{g}}[-]$ represents the geometrical concentration ratio $(3.5 \times)$. The incidence angle to the zenith of the hemispherical dome was determined as a representative incidence angle at each rotation angle because incidence angles are different among the unit lenses, i.e., the position of the hemispherical dome.

Finite element method (FEM) and ray-tracing simulations. To simulate 3D mechanical deformation and heat transfer, a commercial software based on FEM analysis (ANSYS 17.0, ANSYS, Inc., Pennsylvania, USA) was used. The simulation model comprised a single unit module fabricated from a silicone lens, a solar cellwhich was simply assumed to be germanium $(\mathrm{Ge})$ because the Ge subcell is considerably thicker than the GaInP and GaInAs subcells and has a dominant effect on the mechanical deformation and heat transfer in the triple-junction cell used in this study-and a TPU sheet. The details of the boundary conditions in mechanicaldeformation and heat-transfer simulations are provided in Supplementary Figs. 2, 9 , respectively. The lens shape obtained from the mechanical-deformation simulation was imported into the ray-tracing simulation model and the effect of module elongation on the concentrated power on the solar cell was analyzed using a commercial software (LightTools 8.4.0, Synopsys, Inc., California, USA). The raytracing simulation conditions were the same as those mentioned in the "Lens design optimization and ray-tracing simulation" section. In the heat-transfer simulation, steady-state module temperature was simulated assuming a possible higher temperature case.

\section{Data availability}

The data that support the findings of this study are available from the corresponding author upon reasonable request.
Received: 24 June 2020; Accepted: 17 November 2020; Published online: 08 January 2021

\section{References}

1. Haegel, N. M. et al. Terawatt-scale photovoltaics: transform global energy. Science 364, 836-838 (2019).

2. Weber, E. R. Photovoltaics moving into the terawatt age. In SPIE Opt. Eng. + Appl. (SPIE, 2017), https://doi.org/10.1117/12.2277978

3. Yoshikawa, K. et al. Silicon heterojunction solar cell with interdigitated back contacts for a photoconversion efficiency over 26\%. Nat. Energy 2, 17032 (2017).

4. Richter, A., Hermle, M. \& Glunz, S. W. Reassessment of the limiting efficiency for crystalline silicon solar cells. IEEE J. Photovolt. 3, 1184-1191 (2013).

5. Lewis, N. S. Research opportunities to advance solar energy utilization. Science 351, aad1920 (2016).

6. Cashmore, J. S. et al. Improved conversion efficiencies of thin-film silicon tandem (MICROMORPH ${ }^{\mathrm{TM}}$ ) photovoltaic modules. Sol. Energy Mater. Sol. Cells 144, 84-95 (2016).

7. Sugimoto, H. High efficiency and large volume production of CIS-based modules. In 2014 IEEE 40th Photovoltaic Specialist Conf. (PVSC) (PVSC-40) 2767-2770 (IEEE, 2014), https://doi.org/10.1109/PVSC.2014.6925503

8. First Solar. First Solar achieves world record $18.6 \%$ thin film module conversion efficiency. https://investor.firstsolar.com/news/press-releasedetails/2015/First-Solar-Achieves-World-Record-186--Thin-Film-ModuleConversion-Efficiency/default.aspx (2015).

9. Toshiba Corporation. NEDO and Toshiba develops world's largest film-based perovskite photovoltaic module $-703 \mathrm{~cm}^{2}$ module achieves $11.7 \%$ power conversion efficiency-. https://www.toshiba.co.jp/rdc/rd/detail_e/e1806_03. html (2018).

10. Higuchi, H. \& Negami, T. Largest highly efficient $203 \times 203 \mathrm{~mm}^{2}$ $\mathrm{CH}_{3} \mathrm{NH}_{3} \mathrm{PbI}_{3}$ perovskite solar modules. Jpn. J. Appl. Phys. 57, 08RE11 (2018).

11. Mattos, L. S. et al. New module efficiency record: $23.5 \%$ under 1 -sun illumination using thin-film single-junction GaAs solar cells. In 2012 IEEE 38th Photovoltaic Specialist Conf. (PVSC-38) (IEEE, 2012), https://doi.org/ 10.1109/PVSC.2012.6318255.

12. New Energy and Industrial Technology Development Organization (NEDO), Solar cell module with world's highest conversion efficiency of $31.17 \%$ achieved -lightweight, flexible prototype created-. https://www.nedo.go.jp/ english/news/AA5en_100070.html (2016).

13. Ostfeld, A. E., Gaikwad, A. M., Khan, Y. \& Arias, A. C. High-performance flexible energy storage and harvesting system for wearable electronics. Sci. Rep. 6, 26122 (2016)

14. Jokic, P. \& Magno, M. Powering smart wearable systems with flexible solar energy harvesting. In 2017 IEEE Int. Symp. on Circuits and Systems (ISCAS) (IEEE, 2017), https://doi.org/10.1109/ISCAS.2017.8050615

15. Byron Bay Railroad Company. Solar power. http://byronbaytrain.com.au/ sustainability/ (2020).

16. Araki, K., Ji, L., Kelly, G. \& Yamaguchi, M. To do list for research and development and international standardization to achieve the goal of running a majority of electric vehicles on solar energy. Coatings 8, 251 (2018).

17. Rogers, J. A., Someya, T. \& Huang, Y. Materials and mechanics for stretchable electronics. Science 327, 1603-1607 (2010).

18. Kim, D. H. et al. Materials and noncoplanar mesh designs for integrated circuits with linear elastic responses to extreme mechanical deformations. Proc. Natl. Acad. Sci. 105, 18675-18680 (2008).

19. Kim, D. H. et al. Stretchable and foldable silicon integrated circuits. Science 320, 507-511 (2008).

20. Nam, J. et al. Transfer printed flexible and stretchable thin film solar cells using a water-soluble sacrificial layer. Adv. Energy Mater. 6, 1601269 (2016)

21. Nam, J., Seo, B., Lee, Y., Kim, D. H. \& Jo, S. Cross-buckled structures for stretchable and compressible thin film silicon solar cells. Sci. Rep. 7, 7575 (2017).

22. Park, S. II et al. Printed assemblies of inorganic light-emitting diodes for deformable and semitransparent displays. Science 325, 977-981 (2009).

23. Ko, H. C. et al. A hemispherical electronic eye camera based on compressible silicon optoelectronics. Nature 454, 748-753 (2008).

24. Kim, D. H. et al. Dissolvable films of silk fibroin for ultrathin conformal biointegrated electronics. Nat. Mater. 9, 511-517 (2010).

25. Kim, D. H. et al. Epidermal electronics. Science 333, 838-843 (2011).

26. Lipomi, D. J., Tee, B. C. K., Vosgueritchian, M. \& Bao, Z. Stretchable organic solar cells. Adv. Mater. 23, 1771-1775 (2011).

27. Li, L. et al. A solid-state intrinsically stretchable polymer solar cell. ACS Appl. Mater. Interfaces 9, 40523-40532 (2017). 
28. Jinno, H. et al. Stretchable and waterproof elastomer-coated organic photovoltaics for washable electronic textile applications. Nat. Energy 2, 780-785 (2017).

29. Hsieh, Y. T., Chen, J. Y., Shih, C. C., Chueh, C. C. \& Chen, W. C. Mechanically robust, stretchable organic solar cells via buckle-on-elastomer strategy. Org. Electron. 53, 339-345 (2018).

30. Lee, J. et al. Stretchable GaAs photovoltaics with designs that enable high areal coverage. Adv. Mater. 23, 986-991 (2011).

31. Lee, J. et al. Stretchable semiconductor technologies with high areal coverages and strain-limiting behavior: Demonstration in high-efficiency dual-junction GaInP/GaAs photovoltaics. Small 8, 1851-1856 (2012).

32. El-Atab, N., Qaiser, N., Bahabry, R. \& Hussain, M. M. Corrugation enabled asymmetrically ultrastretchable (95\%) monocrystalline silicon solar cells with high efficiency (19\%). Adv. Energy Mater. 9, 1902883 (2019).

33. Luque, A. L. \& Andreev, V. M. Concentrator Photovoltaics Ch. 1 (Springer. com, 2007).

34. Wiesenfarth, M., Philipps, S. P., Bett, A. W., Horowitz, K. \& Kurtz, S. Current Status of Concentrator Photovoltaic (CPV) Technology (Fraunhofer ISE and National Renewable Energy Laboratory, 2017), http://www.ise.fraunhofer.de/ en/publications/veroeffentlichungen-pdf-dateien-en/studien-und-

konzeptpapiere/current-status-of-concentrator-photovoltaic-cpv-technology. pdf

35. Kinsey, G. S. et al. Advancing efficiency and scale in CPV arrays. IEEE J. Photovolt. 3, 873-878 (2013).

36. Ghosal, K. et al. Semprius field results and progress in system development IEEE J. Photovolt. 4, 703-708 (2014).

37. Steiner, M. et al. FLATCON ${ }^{\circledR}$ CPV module with $36.7 \%$ efficiency equipped with four-junction solar cells. Prog. Photovolt. Res. Appl. 23, 1323-1329 (2015).

38. Masuda, T. et al. Static concentrator photovoltaics for automotive applications. Sol. Energy 146, 523-531 (2017).

39. Sato, D. et al. Design of low-concentration static III-V/Si partial CPV module with $27.3 \%$ annual efficiency for car-roof application. Prog. Photovolt. Res. Appl. 27, 501-510 (2019).

40. Feher Helmets. Air conditioned motorcycle helmets. https://feherhelmets. $\mathrm{com} /(2020)$.

41. Yamada, N. et al. Development of silicone-encapsulated CPV module based on LED package technology. In 2013 IEEE 39th Photovoltaic Specialist Conf. (PVSC-39) 0493-0496 (IEEE, 2013), https://doi.org/10.1109/ PVSC.2013.6744197

42. Domínguez, C., Jost, N., Askins, S., Victoria, M. \& Antón, I. A review of the promises and challenges of micro-concentrator photovoltaics. AIP Conf. Proc. 1881, 080003 (2017).

43. Ritou, A., Voarino, P. \& Raccurt, O. Does micro-scaling of CPV modules improve efficiency? A cell-to-module performance analysis. Sol. Energy 173, 789-803 (2018).

44. Lee, K.-T. et al. Concentrator photovoltaic module architectures with capabilities for capture and conversion of full global solar radiation. Proc. Natl. Acad. Sci. 113, E8210-E8218 (2016).

45. Price, J. S. et al. High-concentration planar microtracking photovoltaic system exceeding 30\% efficiency. Nat. Energy 2, 17113 (2017).

46. Li, D. et al. Wafer integrated micro-scale concentrating photovoltaics. Prog. Photovolt. Res. Appl. 26, 651-658 (2018).

47. Ruud, C. J., Price, J. S., Fisher, B., Wang, B. \& Giebink, N. C. Lightweight monolithic microcell CPV for space. In The 7th World Conf. on Photovoltaic Energy Conversion (WCPEC-7) (IEEE, 2018), https://ieeexplore.ieee.org/ document $/ 8548170$

48. Lumb, M. P. et al. A micro-concentrator photovoltaic module incorporating a bifacial silicon solar cell for direct and diffuse light capture. In 2019 IEEE 46th Photovoltaic Specialist Conf. (PVSC-46) (IEEE, 2019), https://doi.org/10.1109/ PVSC40753.2019.8980829

49. Herrero, R. et al. Concentration photovoltaic optical system irradiance distribution measurements and its effect on multi-junction solar cells. Prog. Photovolt. Res. Appl. 20, 423-430 (2012).

50. Algora, C. \& Rey-Stolle, I. Handbook of Concentrator Photovoltaic Technology Ch. 4 (John Wiley \& Sons, Ltd, 2016).
51. Sato, D. \& Yamada, N. Design and testing of highly transparent concentrator photovoltaic modules for efficient dual-land-use applications. Energy Sci. Eng. 8, 779-788 (2020)

52. Insolight SA. THEIA (Translucency \& High Efficiency in Agrivoltaics). https://insolight.ch/agrivoltaics-insolight/. (2020).

53. Askins, S. et al. Performance of hybrid micro-concentrator module with integrated planar tracking and diffuse light collection. In 2019 IEEE 46th Photovoltaic Specialist Conf. (PVSC-46) (IEEE, 2019). https://doi.org/10.1109/ PVSC40753.2019.8980519

54. National Renewable Energy Laboratory (NREL). Reference air mass 1.5 spectra. https://www.nrel.gov/grid/solar-resource/spectra-am1.5.html (2020).

55. Yamada, N. \& Hirai, D. Maximization of conversion efficiency based on global normal irradiance using hybrid concentrator photovoltaic architecture. Prog. Photovolt. Res. Appl. 24, 846-854 (2016).

\section{Acknowledgements}

The authors would like to thank T. Ogiwara of NAMICS Corporation for providing the stretchable conductive paste and technically supporting screen-printing to form the electrode pattern on the stretchable sheet.

\section{Author contributions}

D.S. performed theoretical simulations (lens design optimization, ray-tracing simulation, FEM simulation), module prototyping, and performance evaluation (indoor/outdoor tests). T.M. conducted marketing survey and supported the understanding of the concept of coverage on $3 \mathrm{D}$ curved surfaces. K.A. and M.Y. proposed the idea of low-

concentration static CPV and supported discussions regarding the module design. K.O., A.S., and R.T. contributed to analyses of the concepts. N.Y. developed the concept of stretchable micro-scale CPV and supervised the project. All authors contributed to the discussions and to improvements of this manuscript.

\section{Competing interests}

The authors declare no competing interests.

\section{Additional information}

Supplementary information is available for this paper at https://doi.org/10.1038/s43246020-00106-x.

Correspondence and requests for materials should be addressed to D.S.

Peer review information Primary handling editor: John Plummer

Reprints and permission information is available at http://www.nature.com/reprints

Publisher's note Springer Nature remains neutral with regard to jurisdictional claims in published maps and institutional affiliations.

Open Access This article is licensed under a Creative Commons Attribution 4.0 International License, which permits use, sharing, adaptation, distribution and reproduction in any medium or format, as long as you give appropriate credit to the original author(s) and the source, provide a link to the Creative Commons license, and indicate if changes were made. The images or other third party material in this article are included in the article's Creative Commons license, unless indicated otherwise in a credit line to the material. If material is not included in the article's Creative Commons license and your intended use is not permitted by statutory regulation or exceeds the permitted use, you will need to obtain permission directly from the copyright holder. To view a copy of this license, visit http://creativecommons.org/ licenses/by/4.0/.

(C) The Author(s) 2021 